\title{
Influence of physicians' life stances on attitudes to end-of-life decisions and actual end-of-life decision- making in six countries
}

\author{
$\mathrm{J}$ Cohen, ${ }^{1} \mathrm{~J}$ van Delden, ${ }^{3} \mathrm{~F}$ Mortier, ${ }^{2} \mathrm{R}$ Löfmark, ${ }^{4} \mathrm{M}$ Norup, ${ }^{5} \mathrm{C}$ Cartwright, ${ }^{6} \mathrm{~K}$ Faisst, ${ }^{7}$ \\ C Canova, ${ }^{8}$ B Onwuteaka-Philipsen, ${ }^{9} \mathrm{~J}$ Bilsen, ${ }^{1,2}$ on behalf of the Eureld Consortium
}

${ }^{1}$ End-of-Life Care Research Group, Vrije Universiteit Brussel, Brussels, Belgium; ${ }^{2}$ Centre for Environmental Philosophy and Bioethics, Ghent University, Ghent, Belgium; ${ }^{3}$ Julius Center for Health Science and Primary Care, University Medical Center, Utrecht, The Netherlands;

${ }^{4}$ Centre for Bioethics, LIME, Karolinska Institutet and Uppsala University, Stockholm, Sweden; ${ }^{5}$ Department of Medical Philosophy and Clinical Theory, University of Copenhagen, Copenhagen, Denmark; ${ }^{6}$ Aged Services Learning and Research Collaboration, Southern Cross University, Coffs Harbour, Australia; ${ }^{7}$ University of Zurich, Institute of Social and Preventive Medicine, Zurich, Switzerland:

${ }^{8}$ Department of Environmental Medicine and Public

Health,University of Padua, Padua, Italy; ${ }^{9}$ Department of Public and Occupational Health, EMGO Institute, VU University Medical Center, Amsterdam, The Netherlands

Correspondence to: J Cohen, Vrije Universiteit Brussel, End-of-Life Care Research Group, Department of Medical Sociology and Health Sciences, Laarbeeklaan 103, B1090 Brussels, Belgium; Joachim.Cohen@vub.ac.be

Received 22 December 2006 Revised 10 April 2007

Accepted 1 May 2007

\section{ABSTRACT}

Aim: To examine how physicians' life stances affect their attitudes to end-of-life decisions and their actual end-oflife decision-making.

Methods: Practising physicians from various specialties involved in the care of dying patients in Belgium, Denmark, The Netherlands, Sweden, Switzerland and Australia received structured questionnaires on end-of-life care, which included questions about their life stance. Response rates ranged from $53 \%$ in Australia to $68 \%$ in Denmark. General attitudes, intended behaviour with respect to two hypothetical patients, and actual behaviour were compared between all large life-stance groups in each country.

Results: Only small differences in life stance were found in all countries in general attitudes and intended and actual behaviour with regard to various end-of-life decisions. However, with regard to the administration of drugs explicitly intended to hasten the patient's death (PAD), physicians with specific religious affiliations had significantly less accepting attitudes, and less willingness to perform it, than non-religious physicians. They had also actually performed PAD less often. However, in most countries, both Catholics (up to $15.7 \%$ in The Netherlands) and Protestants (up to $20.4 \%$ in The Netherlands) reported ever having made such a decision. Discussion: The results suggest that religious teachings influence to some extent end-of-life decision-making, but are certainly not blankly accepted by physicians, especially when dealing with real patients and circumstances. Physicians seem to embrace religious belief in a non-imperative way, allowing adaptation to particular situations.

Physicians' attitudes to life and death appear to orient their end-of-life decision-making. ${ }^{1}$ It is important therefore to both assess their attitudes ${ }^{2}$ and understand exactly how these are related to end-of-life decision-making. Research has generally corroborated that (stronger) theistic religious beliefs are associated with lower acceptance of various end-of-life decisions (ELDs), particularly euthanasia. $^{3-9}$ Often this is explained by the traditional viewpoints of Judaism, Catholicism, Protestantism and Islam (or their religious authorities) regarding end-of-life issues, extensively described in the bioethical literature. ${ }^{10-18}$ However, as these traditional religious doctrines are commonly balanced by considerations of due care and general sentiments of humanity and compassion, which come into play in actually dealing with patients, there is some dispute over the decisiveness of statements of doctrine for physicians' actual decision-making. ${ }^{19}$ A specific research question of this study is therefore: are viewpoints from different life stances on different kinds of ELDs, as illustrated in the recent Lancet series, ${ }^{11}{ }^{16} 18$ also translated into attitudes and actual practices of the physicians who adhere to these life stances? We will examine the effect of life stance on physicians':

- general attitudes to different ELDs: non-treatment decisions (NTDs); alleviation of pain and symptoms with a possible life-shortening effect; terminal sedation; and administration of lethal drugs (ie, physician-assisted dying (PAD));

- willingness to make these ELDs, given certain circumstances;

- actual decision-making.

We will also examine whether the country of residence has an effect, making it possible to evaluate also the influence of the surrounding (secular) culture.

\section{METHODS}

\section{Design, sample and questionnaire}

In six European countries, Belgium (Flanders), Denmark, Italy (Emilia-Romagna, Trento, Tuscany and Veneto), The Netherlands, Sweden and Switzerland, and in Australia, a written structured questionnaire was sent to practising physicians from 10 specialties often involved in care of the dying: anaesthesiology, general practice, geriatrics, gynaecology, internal medicine, neurology, nursing home medicine (in The Netherlands), oncology, pulmonology and surgery. ${ }^{40}$ For each country, a random sample of 300 physicians was selected for each specialty, or all physicians if less then 300 were active in that specialty. Questions were asked about general attitudes, intended behaviour and actual practices concerning end-of-life care, and background characteristics of the physicians. Questionnaires were sent in the second half of 2002 (after the euthanasia laws had come into effect in The Netherlands and Belgium) and were processed anonymously. More details can be found elsewhere. $^{4} 20$

In the Italian version of the questionnaire, the question on religious affiliation was omitted in order not to decrease the response rate, hence Italy is not included in the analyses for this paper.

\section{Life stance}

The questionnaire asked: "What do you consider to be your religion or philosophy on life?". Options were: "Roman Catholic", "Protestant", "other 
Table 1 Life stance and importance of life stance in end-of-life decision-making by country

\begin{tabular}{lcccccc}
\hline & Belgium & Denmark & Netherlands & Sweden & Switzerland & Australia \\
\hline Response rate (\%) & 58 & 68 & 61 & 60 & 64 & 53 \\
No of respondents & 1750 & 1217 & 1275 & 1514 & 1397 & 1478 \\
Life stance (\%) & & & & & & \\
$\quad$ Christian & & & & & & \\
$\quad$ Roman Catholic & 64.4 & 1.1 & 28.4 & 4.5 & 30.9 & 19.1 \\
$\quad$ Protestant & 0.8 & 56.9 & 22.1 & 50.6 & 34.7 & 29.2 \\
$\quad$ Orthodox & 0.0 & 0.1 & 0.0 & 1.4 & 0.5 & 1.3 \\
$\quad$ Non-religious & & & & & & \\
$\quad$ Specific philosophy* & 8.8 & 3.1 & 3.3 & 3.8 & 2.1 & 2.6 \\
$\quad$ No specific philosophy & 23.9 & 37.6 & 43.9 & 36.0 & 27.0 & 36.5 \\
$\quad$ Other religions & & & & & & \\
$\quad$ Jewish & 0.1 & 0.1 & 0.2 & 0.7 & 1.1 & 3.4 \\
$\quad$ Muslim & 0.1 & 0.1 & 0.1 & 1.6 & 0.5 & 0.3 \\
$\quad$ Buddhist & 0.2 & 0.1 & 0.2 & 0.1 & 0.5 & 1.9 \\
$\quad$ Hindu & 0.1 & 0.1 & 0.1 & 0.1 & 0.1 & 1.7 \\
$\quad$ Other denomination & 0.5 & 0.3 & 0.7 & 0.7 & 1.1 & 1.1 \\
$\quad$ Religious without denomination & 1.3 & 0.6 & 0.9 & 0.4 & 1.6 & 2.8 \\
Self-reported importance of life & 45.0 & 32.1 & 38.7 & 47.8 & 62 & 54.2 \\
stance in ELDs (\% important & & & & & & \\
or very important) & & & & & & \\
\hline
\end{tabular}

*Usually humanist/existentialist: $94 \%$ in Belgium,79\% in Denmark, 95\% in The Netherlands, 91\% in Sweden, 71\% in Switzerland, $66 \%$ in Australia. The minority of physicians with other specific non-religious philosophies were mostly atheists but with Christian ethics $(1.3-18.4 \%)$ and a small number of Taoists $(0-4 \%)$.

ELD, end-of-life decision.

religion", "non-religious", or "no specific philosophy". If they answered "other religion" or "non-religious", they were asked to specify, respectively, their religion or philosophy on life. All responses were classified into 11 categories of life stance (table 1). Non-religious physicians with a specific philosophy on life included those who attested to a (non-religious) value system (1) known to be shared groupwise and (2) known to offer some kind of guidance for life and death issues (eg, humanism).

\section{Statistical analysis}

Firsly, principal component analysis was performed to reveal the underlying structure of a set of 14 statements ${ }^{4}$ scored on a five-point Likert scale from "totally agree" to "totally disagree". It identified three factors of general attitudes to ELDs. Items with a component loading higher than 0.5 were retained in the factors, and standardised scores were calculated by attributing a weight equal to the factor loading to each salient variable (see appendix). Physicians with higher standardised scores on a factor thus show greater agreement with the statements that define that factor. The mean standardised factor scores (and

\section{Box 1: Description of the two hypothetical patients}

The two patients are 71-year-old cancer patients with extensive brain and bone metastases. They have both had burdensome chemotherapy twice, and having chemotherapy once more would give a limited chance of long-standing remission $(<10 \%)$.

- Case 1: The patient is drowsy or subcomatose and communication is not possible. You estimate the patient's life expectancy (without chemotherapy) to be no more than 2 weeks. Pain can be adequately controlled, but the patient is extremely tired, short of breath and bedridden.

- Case 2: The patient is clear headed and can still communicate. You estimate the patient's life expectancy (without chemotherapy) to be no more than 2 weeks. The patient has pain that is difficult to control despite the use of high doses of analgesics.
95\% CI) of the three factors were compared between the lifestance groups.

Secondly, to describe and compare the willingness to make ELDs given certain (real life) circumstances, two hypothetical cases of a 71-year-old cancer patient with extensive brain and bone metastase ${ }^{20}$ were considered. For both cases, which are described in box 1 , percentages were compared (Pearson $\chi^{2}$ test) of physicians probably or certainly deciding (score 1 or 2 on a five-point Likert scale), both at the request of the patient and without any request, to:

- step up alleviation of pain/symptoms by using drugs such as opioids, taking into account the probability or certainty that this would hasten the end of the patient's life (APS);

- administer drugs, such as benzodiazepines or barbiturates, to keep the patient in deep sedation until death, without giving hydration or nutrition (terminal sedation);

- administer drugs with the explicit intention of hastening the patient's death (PAD).

A possible differential influence of certain circumstances on the willingness of the different life-stance groups to make the respective ELDs was also checked by comparing the differences in scores for case 1 and case 2, and for the presence or absence of an explicit patient request (tested with Kruskal-Wallis).

Thirdly, the actual decision-making in different life-stance groups was compared by examining the percentages ever having actually performed APS, terminal sedation and PAD. Pearson $\chi^{2}$ and Fisher exact tests were used to determine the statistical significance of differences.

In all comparisons, we used only the larger life-stance groups, in view of the reliability of the results.

\section{RESULTS}

Response rates ranged from $53 \%$ in Australia to $68 \%$ in Denmark (table 1).

\section{Life stances}

Physicians separated into four large life-stance groups in all six countries (table 1): Roman Catholics $(1.1 \%$ in Denmark to 


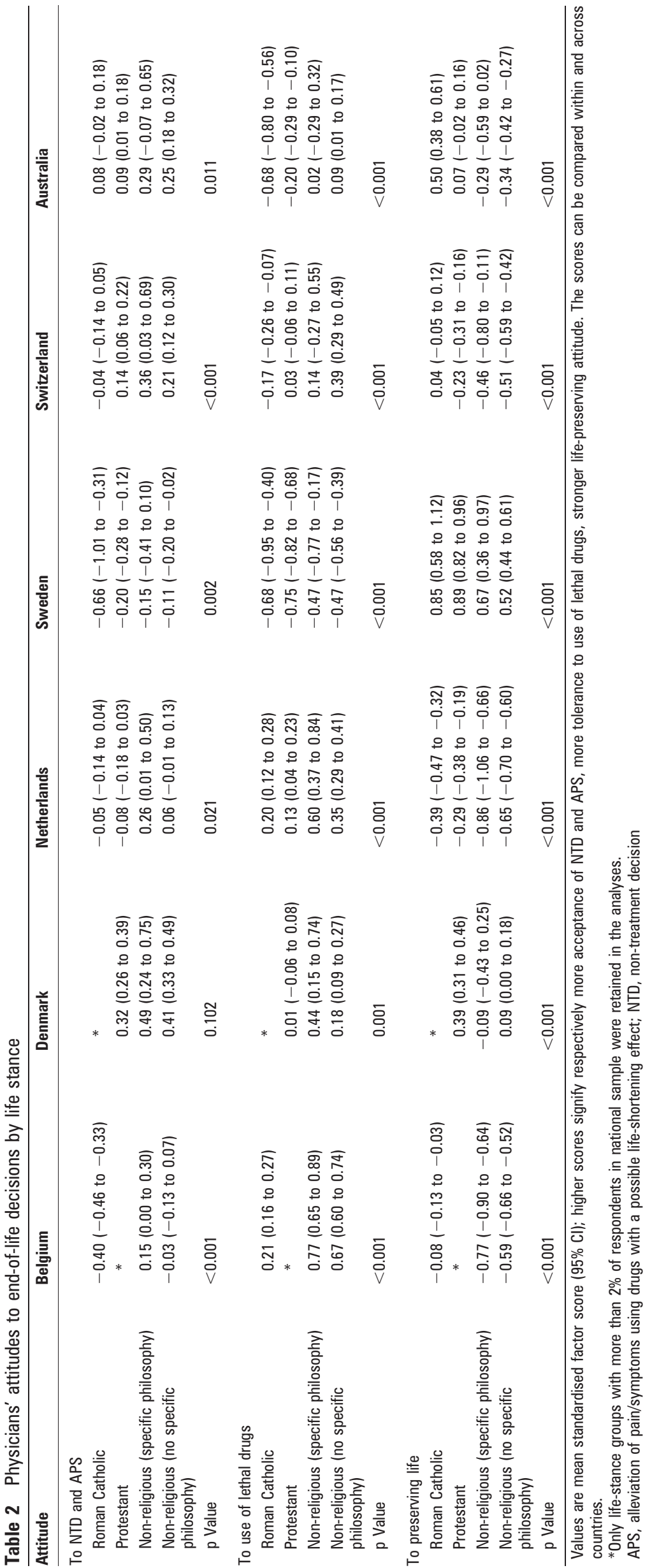


$64.4 \%$ in Belgium); Protestants $(0.8 \%$ in Belgium to $56.9 \%$ in Denmark); non-religious with a specific life philosophy such as humanism (2.1\% in Switzerland to $8.8 \%$ in Belgium); nonreligious with no specific philosophy on life (23.9\% in Belgium to $43.9 \%$ in The Netherlands).

Those who indicated that their life stance is important in their professional attitude to end-of-life decision-making ranged from $32 \%$ of all physicians (with both theistic and non-theistic life stances) in Denmark to $62 \%$ in Switzerland.

\section{Life stance and general attitudes to ELDs}

Three dimensions of attitudes to ELDs were distinguished by principal component analysis (appendix), for which significant differences were found between life-stance groups (table 2).

Apart from in Denmark, physicians in the religious categories were significantly less accepting of NTD and APS than physicians with non-religious life stances (especially in
Belgium). In Sweden and Switzerland, Roman Catholic physicians were less accepting than Protestant physicians.

Differences between life stances were much more pronounced for attitudes to the use of lethal drugs (PAD). In all countries, but most notably in Belgium, non-religious physicians were more accepting than religious physicians. In Switzerland and Australia, Protestants were also more accepting than Catholics. Among non-religious physicians, those with a specific life philosophy tended to be more accepting than those without a specific life philosophy in Belgium $(p=0.165)$ and The Netherlands $(p=0.032)$.

Similar but inverse patterns were found for attitudes to life preservation, with particularly high scores for Swedish physicians.

\section{Hypothetical decision-making by life stance in different circumstances}

For willingness to perform APS, no, or barely, significant differences were found between religious and non-religious

Table 3 Life stance and hypothetical decision-making in different circumstances

\begin{tabular}{|c|c|c|c|c|c|c|c|c|c|c|c|c|}
\hline \multirow[b]{2}{*}{ Decision } & \multicolumn{2}{|l|}{ Belgium } & \multicolumn{2}{|c|}{ Denmark } & \multicolumn{2}{|c|}{ Netherlands } & \multicolumn{2}{|l|}{ Sweden } & \multicolumn{2}{|c|}{ Switzerland } & \multicolumn{2}{|c|}{ Australia } \\
\hline & Case 1 & Case 2 & Case 1 & Case 2 & Case 1 & Case 2 & Case 1 & Case 2 & Case 1 & Case 2 & Case 1 & Case 2 \\
\hline \multicolumn{13}{|l|}{ APS at patient's request $\dagger$} \\
\hline Roman Catholic & 95 & 98 & * & * & 93 & 97 & 78 & 88 & 82 & 89 & 94 & 96 \\
\hline Protestant & * & * & 87 & 98 & 93 & 99 & 88 & 93 & 82 & 89 & 95 & 98 \\
\hline Non-religious (specific philosophy) & 98 & 99 & 95 & 100 & 95 & 100 & 84 & 98 & 89 & 96 & 97 & 97 \\
\hline Non-religious (no specific philosophy) & 97 & 98 & 87 & 100 & 93 & 98 & 88 & 95 & 89 & 94 & 97 & 98 \\
\hline $\mathrm{p}$ Value & 0.134 & 0.670 & 0.313 & 0.055 & 0.916 & 0.218 & 0.136 & 0.058 & 0.017 & 0.063 & 0.153 & 0.130 \\
\hline \multicolumn{13}{|l|}{ APS on own initiative } \\
\hline Roman Catholic & 83 & 79 & * & * & 63 & 45 & 68 & 71 & 74 & 69 & 86 & 71 \\
\hline Protestant & * & * & 82 & 78 & 70 & 49 & 80 & 76 & 69 & 64 & 80 & 65 \\
\hline Non-religious (specific philosophy) & 83 & 83 & 87 & 81 & 67 & 45 & 84 & 78 & 74 & 70 & 92 & 79 \\
\hline Non-religious (no specific philosophy) & 81 & 76 & 78 & 77 & 67 & 47 & 78 & 74 & 79 & 72 & 87 & 65 \\
\hline $\mathrm{p}$ Value & 0.692 & 0.188 & 0.215 & 0.733 & 0.342 & 0.772 & 0.092 & 0.587 & 0.019 & 0.094 & 0.013 & 0.121 \\
\hline \multicolumn{13}{|l|}{ Terminal sedation at patient's request $\dagger$} \\
\hline Roman Catholic & 81 & 78 & * & * & 74 & 62 & 68 & 69 & 66 & 74 & 59 & 49 \\
\hline Protestant & * & * & 52 & 47 & 71 & 70 & 50 & 50 & 70 & 73 & 67 & 55 \\
\hline Non-religious (specific philosophy) & 87 & 85 & 49 & 54 & 75 & 80 & 62 & 61 & 78 & 78 & 70 & 54 \\
\hline Non-religious (no specific philosophy) & 84 & 80 & 56 & 52 & 71 & 66 & 56 & 55 & 76 & 76 & 72 & 66 \\
\hline $\mathrm{p}$ Value & 0.121 & 0.122 & 0.297 & 0.159 & 0.823 & 0.048 & 0.010 & 0.013 & 0.037 & 0.651 & 0.002 & $<0.001$ \\
\hline \multicolumn{13}{|l|}{ Terminal sedation on own initiative } \\
\hline Roman Catholic & 60 & 38 & * & * & 38 & 10 & 49 & 33 & 54 & 33 & 46 & 22 \\
\hline Protestant & * & * & 41 & 21 & 37 & 8 & 34 & 21 & 48 & 31 & 51 & 28 \\
\hline Non-religious (specific philosophy) & 63 & 43 & 50 & 31 & 49 & 16 & 36 & 14 & 43 & 25 & 50 & 29 \\
\hline Non-religious (no specific philosophy) & 57 & 32 & 42 & 26 & 36 & 11 & 40 & 21 & 56 & 35 & 53 & 26 \\
\hline $\mathrm{p}$ Value & 0.295 & 0.023 & 0.566 & 0.097 & 0.485 & 0.470 & 0.045 & 0.086 & 0.072 & 0.533 & 0.324 & 0.444 \\
\hline \multicolumn{13}{|l|}{$\mathrm{PAD}$ at patient's request ${ }^{\dagger}$} \\
\hline Roman Catholic & 46 & 39 & * & * & 45 & 47 & 6 & 8 & 18 & 14 & 12 & 11 \\
\hline Protestant & * & * & 20 & 19 & 42 & 49 & 5 & 3 & 24 & 23 & 22 & 18 \\
\hline Non-religious (specific philosophy) & 81 & 79 & 38 & 35 & 65 & 64 & 7 & 4 & 29 & 43 & 30 & 27 \\
\hline Non-religious (no specific philosophy) & 65 & 65 & 25 & 26 & 50 & 61 & 9 & 7 & 40 & 33 & 29 & 29 \\
\hline $\mathrm{p}$ Value & $<0.001$ & $<0.001$ & 0.012 & 0.004 & 0.019 & $<0.001$ & 0.111 & 0.011 & $<0.001$ & $<0.001$ & $<0.001$ & $<0.001$ \\
\hline \multicolumn{13}{|l|}{ PAD on own initiative } \\
\hline Roman Catholic & 22 & 9 & $*$ & * & 13 & 5 & 5 & 3 & 10 & 7 & 8 & 4 \\
\hline Protestant & $*$ & $*$ & 17 & 9 & 13 & 3 & 5 & 2 & 13 & 9 & 17 & 10 \\
\hline Non-religious (specific philosophy) & 41 & 26 & 35 & 22 & 15 & 5 & 4 & 2 & 7 & 4 & 24 & 14 \\
\hline Non-religious (no specific philosophy) & 33 & 15 & 21 & 14 & 13 & 4 & 6 & 2 & 18 & 11 & 19 & 10 \\
\hline $\mathrm{p}$ Value & $<0.001$ & $<0.001$ & 0.014 & 0.002 & 0.966 & 0.622 & 0.872 & 0.819 & 0.008 & 0.285 & $<0.001$ & 0.019 \\
\hline
\end{tabular}

Values are the percentages probably or certainly agreeing to make a given end-of-life decision; $p$ values are from Pearson $\chi^{2}$ test .

Case 1: the patient is drowsy or subcomatose and communication is not possible. You estimate the patient's life expectancy (without chemotherapy) to be no more than 2 weeks. Pain can be adequately controlled, but the patient is extremely tired, short of breath and bedridden.

Case 2: the patient is clear headed and can still communicate. You estimate the patient's life expectancy (without chemotherapy) to be no more than 2 weeks. The patient had pain that is difficult to control despite the use of high doses of analgesics.

${ }^{*}$ Only life-stance groups with more than $2 \%$ of respondents in national sample were retained in the analyses

†For case 1 (communication not possible) "at patient request" was defined as a request stated in an advanced directive.

APS, alleviation of pain/symptoms using drugs with a possible life-shortening effect; PAD, physician-assisted death. 
Table 4 Physicians' life stance and actual end-of-life decision-making

\begin{tabular}{|c|c|c|c|c|c|c|}
\hline End-of-life decision & Belgium & Denmark & Netherlands & Sweden & Switzerland & Australia \\
\hline \multicolumn{7}{|l|}{ Ever performed APS? } \\
\hline Roman Catholic & 84.0 & * & 91.6 & 55.6 & 64.8 & 86.2 \\
\hline Protestant & * & 94.6 & 90.5 & 66.0 & 70.7 & 85.4 \\
\hline Non-religious (specific philosophy) & 85.0 & 97.3 & 97.5 & 78.4 & 85.2 & 92.1 \\
\hline Non-religious (no specific philosophy) & 81.1 & 96.1 & 92.8 & 70.1 & 73.6 & 89.4 \\
\hline $\mathrm{p}$ Value & 0.550 & 0.580 & 0.383 & 0.026 & 0.016 & 0.222 \\
\hline \multicolumn{7}{|l|}{ Ever performed terminal sedation? } \\
\hline Roman Catholic & 30.7 & $*$ & 40.4 & 30.8 & 23.9 & 31.8 \\
\hline Protestant & * & 29.4 & 36.2 & 22.2 & 27.4 & 30.5 \\
\hline Non-religious (specific philosophy) & 35.5 & 24.3 & 45.0 & 37.0 & 39.3 & 24.3 \\
\hline Non-religious (no specific philosophy) & 27.2 & 32.0 & 44.8 & 27.6 & 28.4 & 35.1 \\
\hline $\mathrm{p}$ Value & 0.020 & 0.658 & 0.127 & 0.017 & 0.216 & 0.313 \\
\hline \multicolumn{7}{|l|}{$\begin{array}{l}\text { Ever performed PAD at patient's } \\
\text { request? } \$\end{array}$} \\
\hline Roman Catholic & 6.1 & * & 15.7 & 0.0 & 3.4 & 2.9 \\
\hline Protestant & * & 4.9 & 20.4 & 0.4 & 5.1 & 2.4 \\
\hline Non-religious (specific philosophy) & 14.5 & 16.2 & 34.1 & 0.0 & 14.8 & 5.3 \\
\hline Non-religious (no specific philosophy) & 11.1 & 6.4 & 22.9 & 2.5 & 7.2 & 6.3 \\
\hline $\mathrm{p}$ Value & $<0.001$ & 0.036 & 0.009 & $0.009 \dagger$ & 0.021 & 0.018 \\
\hline
\end{tabular}

physicians in most countries (table 3). Significantly less willingness was found among religious physicians in Switzerland for case 1 (with or without a request) and in Australia for case 1 (without a request).

Although differences were small, in Australia and Switzerland religious physicians tended to be less inclined than non-religious ones to perform terminal sedation when the patient requested it. In these countries, Roman Catholics generally tended to be least inclined. In Sweden, however, Catholics were more inclined to perform terminal sedation than Protestant and non-religious physicians. In the absence of any request, no differences were found between the life-stance groups in their willingness to perform sedation, except in Sweden for case 1, where Catholic physicians were more inclined than physicians with any other life stance to provide it, and in Belgium for case 2 where Catholics were more inclined to provide it than non-religious physicians without a specific life philosophy $(p=0.023)$.

In all countries, religious physicians were clearly less inclined than non-religious physicians to perform PAD at the patient's request (except in Sweden for case 1 and for Swedish Catholics in case 2). Among non-religious physicians in Belgium, Denmark (case 1), and The Netherlands (case 1), those with a specific life philosophy were more inclined to do so than those without such a life stance. A differentiation was also found among religious physicians: Roman Catholics were less inclined than Protestants to perform PAD at the patient's request in both cases in Switzerland and in Australia. When no request was made, the willingness to perform PAD decreased considerably (most in The Netherlands). It was lowest among Swedish Protestant physicians for case $2(1.7 \%)$ and highest among non-religious Belgian physicians with a specific life philosophy for case 1 (41.4\%). Differences between life stances in The Netherlands, Sweden and Switzerland were no longer significant (case 2).

A differential influence by circumstance was found (not presented in table 3). A patient request influenced religious physicians less than non-religious physicians to perform PAD. The effect was comparable for terminal sedation (Belgium and
Sweden) and for APS (Australia and Belgium). In Switzerland and Australia, the patient's request also tended to be more important for Protestants than for Catholics. There was only a marginal difference in the effect of clinical circumstances (case 2 vs case 1 ) on the willingness to make any ELD.

\section{Life stance and actual decision-making}

Differences in actual decision-making about APS and terminal sedation were small between life stances (table 4). APS had been performed more often by non-religious than by religious physicians and by Protestants than by Catholics in Sweden and in Switzerland. Terminal sedation had been performed significantly more often by non-religious physicians with a specific life philosophy in Sweden and Belgium; however, it was also a relatively common practice among religious physicians, particularly Catholics (from $23.9 \%$ in Switzerland to $40.4 \%$ in The Netherlands).

For PAD, differences were more marked. Non-religious physicians, particularly those with a specific philosophy such as humanism (in Belgium, Denmark, The Netherlands, Switzerland), had performed a PAD more often. In Sweden, the proportion ever having done so was very low, with no Roman Catholic or non-religious physician without a specific life philosophy ever having performed a PAD and only $2.5 \%$ of the non-religious physicians with a specific life philosophy having done so. In comparison, in The Netherlands, $15.7 \%$ of Catholic and $20.4 \%$ of Protestant physicians had ever performed a PAD.

\section{DISCUSSION}

Our findings show that physicians' life stances may result in different ELD-making, as suggested by Wenger and Carmel. ${ }^{3}$ Whereas moderate differences were found between life stances with respect to attitudes to, and actual making of nontreatment decisions, as well as of stepping up alleviation of pain/symptoms with a possible life-shortening effect, or terminal sedation, these differences were very large with respect to the use of drugs with the explicit intention of hastening the patient's death (ie, PAD). Although life stance does indeed seem 
to influence both attitudes and actual behaviour, there seems to be an even larger effect of the country of residence, possibly indicating that the (country-specific) surrounding culture is a more relevant determinant of behaviour than (theoretical) differences in the teachings of various life stances.

Our study had a large-scale, cross-national design to allow investigation of the relationship between life stance and ELDs, and also to take account of variation in religious cultural backgrounds (eg, history and patterns of secularisation). A major strength is that the study describes attitudes, as well as intended and actual behaviour. The study had certain limitations. Firstly, the life stance variable was solely based on selfdeclaration. The question also used a general category of "Protestant", which did not allow discrimination of patent differences with respect to ELDs between liberal, moderate and conservative Protestant churches. ${ }^{21}$ Secondly, to maintain an acceptable response rate, the life-stance question was omitted in Italy. Therefore we could not include this country with a strong Roman Catholic cultural background.

Differences identified between physicians with different life stances in attitudes, hypothetical behaviour and actual decisionmaking can be discussed in the framework of viewpoints and teachings of different life stances on NTDs, possibly life-shortening pain and symptom alleviation, terminal sedation, and PAD.

The finding of generally small differences between Christian (Protestant and Roman Catholic) life stances and non-religious life stances in the acceptance, as well as the actual practice, of NTDs and possibly life-shortening escalation of pain/symptomalleviating drugs can be seen in accordance with these religions' acceptance of the human condition ${ }^{16}$ and inevitability of death, ${ }^{10} 1316^{22-24}$ considerations of compassion, the doctrine of double effect, ${ }^{13}$ or rather the psychological difference between "doing" and "allowing". The fact that the use of opioids rarely actually shortens life ${ }^{25}$ may be an additional explanation for the relatively positive attitude of, and frequent practice by, both religious and non-religious physicians.

The minor differences between religious and non-religious physicians in their approval of terminal sedation may be explained in a similar way. However, sedation has a particular position in Christian doctrine, as the use of drugs is regarded as wrong (particularly in Catholicism ${ }^{13}{ }^{24}$ ), as it deprives the dying person of consciousness, thus taking away their final opportunity for repentance and meeting Christ in full consciousness. ${ }^{26}$ Yet our findings show that, in the absence of any request, Catholics, Protestants and non-religious physicians were almost equally willing to sedate patients. In Sweden, Catholics even tended to be more willing. Furthermore, relatively small differences were found in practice. In some countries (eg, Belgium) it was relatively common among Catholics. Terminal sedation thus seems to be morally acceptable to Catholics (and Protestants), whereas the "doctrinal teachings" do not accept this unconditionally. ${ }^{17}{ }^{27}$

Official viewpoints on PAD (including euthanasia and physician-assisted suicide) are very clear. Not only in traditional doctrines, but also among contemporary official Christian viewpoints, it is considered morally wrong. ${ }^{28}$ This is reflected in our results, showing a considerably lower acceptance of, and willingness to perform, PAD, as well as a lower frequency of actually performing it among religious physicians. Rejection of divine authority explains both why self-determination is considered as a prime right and why euthanasia is more willingly accepted by nonreligious physicians, in particular those with specific life philosophies such as humanism. ${ }^{13}$ Secular culture has put a relatively high value on self-determination in life (and death) choices. Moderate and liberal Protestantism's appraisal of individual conscience and responsibility (in life choices) possibly explains their tendency to accept euthanasia more readily than Catholics. In Catholicism (and in conservative Protestantism), the individual is neither the author of his own life nor the arbiter of his own death, but a steward of God's sacred gift of life ${ }^{1024}$ Therefore, the Roman Catholic central authority uniformly declares euthanasia to be immoral and equivalent to killing (eg, in the official declaration on euthanasia). ${ }^{29}$ Our results show that Catholics were indeed generally much less inclined to accept (or to perform) PAD (including euthanasia and physician-assisted suicide) than nonCatholic physicians.

However, notwithstanding the Roman Catholic Church's blank rejection of euthanasia, relatively high percentages of Catholics seemed to be open to the practice of euthanasia: in The Netherlands, up to $47.3 \%$ of Roman Catholics said that they would consider performing euthanasia (ie, PAD at the patient's request) on a hypothetical patient, and a nonnegligible percentage of Roman Catholics admitted to having performed PAD (2.9\% in Australia, 3.4\% in Switzerland, $6.1 \%$ in Belgium, and $15.7 \%$ in The Netherlands). Moreover, physicians with a life stance seemingly connected with an absolutist moral orientation $^{16}$ are sensitive to the peculiarity of circumstances. Our data show that a considerably higher proportion of religious physicians are willing to administer lethal drugs at the patients' request than in the absence of any request. Religious physicians are thus to some extent willing to comply with patients' explicit requests.

Although relatively large differences were found depending on the physician's life stance, much larger differences were found depending on the country of residence. For PAD, a high acceptance and a high frequency of physicians ever performing these actions was found in Belgium and The Netherlands, but in Sweden it was very low. The circumstances of the decisionmaking, such as the presence of a patient request, also appeared to play a larger role in some countries than in others (eg, it appeared to be a more important factor in the acceptability of PAD for Dutch physicians than for Belgian physicians). Moreover, the country of residence was also related to the way in which physicians with different life stances framed their opposition. Belgian and Dutch Catholics were relatively accepting of the use of lethal drugs, and were even more accepting than non-religious physicians from the other countries studied (most notably Sweden). This is also translated into actual behaviour: Dutch Catholic physicians more often performed PAD than non-religious ones in any other country studied. Being a Roman Catholic in countries such as Belgium and The Netherlands implies less commitment to the Vatican's rejection of euthanasia than in the other countries. ${ }^{30}$ Moreover, in Sweden and The Netherlands, Roman Catholics were more tolerant of physician-assisted suicide than Protestants, although in other countries the converse was true.

These differences can partially be explained by the surrounding secular culture (and the strength of the voice of the religious authorities)..$^{15} 28$ Physicians in a society that values individual choice and self-determination with regard to ways of life are more likely to also value individual choice and self-determination with regard to (ways of) death, even if they are religious. ${ }^{31}$ It is also possible, however, that other factors contribute to the tolerance of physicians to $\mathrm{PAD}$ (eg, low or high participation of patients in decision-making). It can be safely hypothesised that the actual or imminent achievement of legal status, as is the case in The Netherlands, Switzerland and Belgium, is a major cultural factor determining attitudes and practice. 


\section{GENERAL CONCLUSIONS}

We have shown that the teachings of religious bodies indeed influence end-of-life decision-making, but are certainly not blankly accepted by physicians. The effect of doctrinal teachings is somewhat clearer on general attitudes to ELDs. However, they tend to have less effect in more realistic cases and specific circumstances. There is thus incongruence between official doctrinal views about ELDs and the actual stances of the followers of those doctrines in real situations. It can perhaps be explained by the fact that most people embrace (theistic) belief not in strict metaphysical terms, but in non-imperative ways, allowing adaptation to particular situations-for instance, to the needs and wishes of the dying and to considerations of humaneness.

Acknowledgements: We acknowledge all physicians who provided the data, all research assistants on the Eureld Project, all national and regional medical associations and other authoritative bodies that supported the study, and the national advisory boards for their support. We also thank Johan Vanoverloop for statistical assistance with this article. The Eureld Consortium is: Australia: Gail Williams, Malcolm Parker (University of Queensland), Margaret Steinberg (Queensland University of Technology); Belgium: Luc Deliens (Vrije Universiteit Brussel, Brussels), Julie van Geluwe, (Ghent University, Ghent); Denmark: Annemarie Dencker, Anna Paldam Folker (University of Copenhagen, Copenhagen); Italy: Guido Miccinesi, Riccardo Cecioni (Center for Study and Prevention of Cancer, Florence), Lorenzo Simonato (University of Padua, Padua), Silva Franchini (Local Health Authority, Trento), Alba Carola Finarelli (Regional Department of Health, Bologna); The Netherlands: Gerrit van der Wal (Vrije UniversitietMedical Center, Amsterdam), Paul J van der Maas, Agnes van der Heide (Erasmus MC, University Medical Center, Rotterdam); Sweden: Tore Nilstun (University of Lund, Lund); Switzerland: Georg Bosshard, Susanne Fischer, Ueli Zellweger (University of Zurich, Zurich).

Funding: This study was supported by a grant from the Fifth Framework Program of the European Commission, Brussels, Belgium (contract glrt-1999-30859). The Australian part of the study was supported by a grant from the National Health \& Medical Research Council of the Australian government.

Competing interests: None.

\section{REFERENCES}

1. Mortier F, Bilsen J, Vander Stichele RH, et al. Attitudes, sociodemographic characteristics, and actual end-of-life decisions of physicians in Flanders, Belgium. Med Decis Making 2003;23:502-10.

2. Forde R, Aasland OG, Falkum E. The ethics of euthanasia: attitudes and practice among Norwegian physicians. Soc Sci Med 1997;45:887-92.

3. Wenger NS, Carmel S. Physicians' religiosity and end-of-life care attitudes and behaviors. Mt Sinai J Med 2004;71:335-43.

4. Miccinesi G, Fischer S, Paci E, et al. Physicians' attitudes towards end-of-life decisions: a comparison between seven countries. Soc Sci Med 2005;60:1961-74.
5. Neumann JK, Olive KE. Physician values and medical decisions. South Med J 2004;97:793.

6. Baume $\mathbf{P}, \mathrm{O}^{\prime}$ Malley E, Bauman A. Professed religious affiliation and the practice of euthanasia. J Med Ethics 1995:21:49-54.

7. Kaldjian LC, Jekel JF, Bernene JL, et al. Internists' attitudes towards terminal sedation in end of life care. J Med Ethics 2004;30:499-503.

8. Cohen J, Marcoux I, Bilsen J, et al. Trends in acceptance of euthanasia among the general public in 12 European countries (1981-1999). Eur J Public Health 2006;16:663-9.

9. Fischer S, Bosshard G, Faisst K, et al. Swiss doctors' attitudes towards end-of-life decisions and their determinants: a comparison of three language regions. Swiss Med Wkly 2006;136:370-6.

10. Larue GA. Euthanasia and religion. A survey of the attitudes of world religions to the right-to-die. Los Angeles: The Hemlock Society, 1985.

11. Baggini J, Pym M. End of life: the humanist view. Lancet 2005;366:1235-7.

12. Coleson RE. Contemporary religious viewpoints on suicide, physician-assisted suicide, and voluntary active euthanasia. Duquesne Law Rev 1996;35:43-80.

13. Donovan GK. Decisions at the end of life: Catholic tradition. Christ Bioeth 1997:3:188-203.

14. Engelhardt HT. Physician-assisted death: doctrinal develoment vs. Christian tradition. Christ Bioeth 1998;4:115-21.

15. Engelhardt HT. Physician-assisted suicide reconsidered: dying as a Christian in a post-Christian age. Christ Bioeth 1998;4:143-67.

16. Engelhardt HT Jr, Iltis AS. End-of-life: the traditional Christian view. Lancet 2005;366:1045-9.

17. Pauls M, Hutchinson RC. Bioethics for clinicians. 28. Protestant bioethics. CMAJ 2002;166:339-43.

18. Markwell H. End-of-life: a catholic view. Lancet 2005;366:1132-5.

19. Mahawar KK. End-of-life issues. Lancet 2005:366:1848.

20. Onwuteaka-Philipsen BD, Fisher S, Cartwright C, et al. End-of-life decision making in Europe and Australia: a physician survey. Arch Intern Med 2006;166:921-9.

21. Burdette AM, Hill TD, Moulton BE. Religion and attitudes toward physician-assisted suicide and terminal palliative care. J Sci Study Relig 2005;44:79-93.

22. Childress JF. Religious viewpoints. In: Emanuel LL, ed. Regulating how we die: the ethical, medical, and legal issues surrounding physician-assisted suicide. Cambridge, MA: Harvard University Press, 1998:120-47.

23. Cozby D. Prolonging life: an Orthodox Christian perspective. Christ Bioeth 1997;3:204-21

24. Kopfensteiner TR. Death with dignity: a Roman Catholic perspective. Linacre 0 1996;63:64-75

25. Sykes N, Thorns A. The use of opioids and sedatives at the end of life. Lancet Oncol 2003;4:312-18

26. Melton J, Manning C. The churches speak on euthanasia: official statements from religious bodies and ecumenical organizations. Detroit: Gale Research, 1991.

27. Walter JJ. Terminal sedation: a Catholic perspective. Update 2002;18:6-8, 12.

28. Cohen J, Marcoux I, Bilsen J, et al. European public acceptance of euthanasia: socio-demographic and cultural factors associated with the acceptance of euthanasia in 33 European countries. Soc Sci Med 2006;63:743-56.

29. Snelling PC. Consequences count: against absolutism at the end of life. J Adv Nurs 2004; 46:350-7.

30. Hamil-Luker J, Smith C. Religious authority and public opinion on the right to die. Sociol Relig 1998;59:373-91.

31. Kasachkoff T. Euthanasia and religious belief: the importance of how we frame the questions. Int J App/ Philos 1991;6:37-44.

\section{APPENDIX}

Principal component analysis: retained items and their component loadings

\begin{tabular}{|c|c|c|c|c|}
\hline & Item & $\begin{array}{l}\text { Attitude to } \\
\text { NTD \& APS }\end{array}$ & $\begin{array}{l}\text { Attitude to } \\
\text { using lethal drugs }\end{array}$ & $\begin{array}{l}\text { Life preserving } \\
\text { attitude }\end{array}$ \\
\hline 1 & $\begin{array}{l}\text { Physicians should comply with a patient's request to withhold or withdraw } \\
\text { life-sustaining treatment }\end{array}$ & 0.79 & - & - \\
\hline 3 & $\begin{array}{l}\text { A person should have the right to decide whether or not to hasten } \\
\text { the end of his or her life }\end{array}$ & - & 0.70 & -0.78 \\
\hline 5 & $\begin{array}{l}\text { The use of drugs in lethal doses on the explicit request } \\
\text { of the patient is acceptable for patients with a terminal illness } \\
\text { with extreme uncontrollable pain or other distress }\end{array}$ & - & 0.87 & - \\
\hline 6 & $\begin{array}{l}\text { If a terminally ill patient is suffering unbearably and is not } \\
\text { capable of making decisions, the physician should be allowed } \\
\text { to administer drugs in lethal doses }\end{array}$ & - & 0.81 & - \\
\hline 7 & $\begin{array}{l}\text { Permitting the use of drugs in lethal doses on the explicit request of the } \\
\text { patient will harm the relationship between patients and physicians }\end{array}$ & - & - & 0.77 \\
\hline
\end{tabular}

